\title{
Establishing the Differences in the Phonological Structures of the Tugen Sub-dialects
}

Nancy Chebet*, Phylis Bartoo

Department of Literature, Languages and Linguistics, Egerton University Kenya

DOI: $10.36348 /$ SIJLL.2019.v02i08.002

| Received: 13.10.2019 | Accepted: 21.10.2019| Published: 27.10.2019

*Corresponding author: Nancy Chebet

\section{Abstract}

The study aimed at identifying and describing the phonological differences between Somor and Aror sub-dialects of the Tugen dialect of the Kalenjin language. The Kalenjin language is characterised by eight dialects of which Tugen is one. These dialects can be mapped according to the geographical location of speakers. Of particular interest is the fact that there exists a dialect continuum, where neighbouring groups understand each other well, while mutual intelligibility decreases gradually to near-zero depending on the geographical distance. Even within given dialects, variations exist to significant levels. The study was guided by Natural Generative Phonology. Stratified and random sampling procedures were used to get samples of Somor and Aror speakers from the population of those who practice in the selected domains in Torongo and Kapuskei locations of Baringo County. The data for the study was a Swadesh list of one hundred and fifty words and fifty sentences. These were drawn from the fields of education, domestic life, religion, health and administration. Data was collected by use of language performance test, which was recorded, on an audiotape. These words were written in gloss and transcribed using the IPA symbols. This was in preparation for the phonological analysis, which was done by using Natural Generative Phonology and Descriptive Linguistics. This study will be an addition to the knowledge in the area of theoretical linguistics of Nilotic languages and Kenyan languages in general.

Keywords: Dialect, Phonology, Language.

Copyright @ 2019: This is an open-access article distributed under the terms of the Creative Commons Attribution license which permits unrestricted use, distribution, and reproduction in any medium for non-commercial use (NonCommercial, or CC-BY-NC) provided the original author and source are credited.

\section{INTRODUCTION}

No human language is fixed uniform or unvarying. All languages show internal variation. The actual usage varies from group to group and from speaker to speaker in terms of pronunciation, choice of words or meanings. Similarly, dialect clusters within a given geographical area tend to be more intelligible amongst each other than dialect clusters that are more distant even though they belong to the same language group. There are however unique features in a given dialect which sets it off from other dialects in the same cluster. The existence of these features, therefore, enables as to draw dialect boundaries, therefore setting one dialect off from the others. This study was basically a descriptive study of Somor and Aror sub-dialects of Tugen dialect of the Kalenjin language. The study was informed by the relatedness of the sub-dialects and the geographical proximity of the areas inhabited by the speakers of the two sub-dialects to one another. The study, therefore, set out to find the extent of the phonological differences between these two subdialects.
The Tugen dialect is spoken in the southeastern part of the Rift Valley province of Kenya. It is part of the Nilotic group of languages. Dialects closely related to Tugen are the Nandi, Kipsigis, Keiyo, Marakwet, Pokot and Sabaot. According to the last population census the Tugen number was around 200,000. The Tugen dialect has two major sub-dialects. The Southern Tugen who are known as Somor and are also referred to as Lembus and the Northern Tugen, who are known as Aror. Somor occupy Eldama Ravine Division, and Aror occupy Kabartonjo Division. These sub-dialects tend to understand each other, though mutual intelligibility decreases to nearly zero because of geographical distance resulting in variations at significant levels.

The Tugen dialect has been presented as a composite dialectal group. However, within Tugen, are different sub-dialects that have specific delineating characteristics in their own right. These sub-dialects have not been characterised and have all along been put together as Tugen in the context of it being seen as one 
dialect. This study is therefore geared towards pointing out the phonological differences in the sub-dialects.

\section{LITERATURE REVIEW}

\section{Dialectological Studies on Other Languages}

Muazu [1] carried out a study on the Mishap:

People, Language and Dialects. He identified two dialects, Longman and Jibaam. He is of the view that the Longman dialect is regarded as the prestige dialect. The Jibaam dialect is regarded as less prestigious, though its speakers consider it to be more prestigious because of its vocabulary. Whereas his work dwelt on which dialect is more prestigious than the other, the present one studied the phonological differences of the Tugen sub-dialects.

Mambwe [2] did a dialectal study on the linguistic variations of Kaonde. He points out that the three Kaonde dialects manifested dialectal variations at various levels of linguistic analysis and that the Mumbwa dialect displayed more variations in relation to the other dialects investigated. On the other hand, the standard and Lubange Solwezi, dialects were found to display minimal linguistic variations between them because of their geographical closeness, and therefore convergence was found to have played a role in reducing the linguistic variations between the two dialects. There are also more lexical differences exhibited among the dialects, followed by syntactic and phonological variations. Morphological variations were found to be few among the three dialects. Whereas this study looked at the lexical morphological and phonological differences, the current one studied phonological differences in Aror and Somor of the Tugen dialect.

\section{Dialectological Studies on Nilotic languages}

The Yoruba language of Yoruba-land of Nigeria consists of several dialects. These can be classified into three major dialect areas: North West, Central and Southeast. In the North-West Yoruba dialect, the proto-Yoruba /gh, the velar fricative [ ] and /gw/ have merged into /w/. The upper vowels /i/ and $/ \mathrm{u} /$ are raised and merged with $/ \mathrm{i} /$ and $/ \mathrm{u} /$, resulting in a vowel system with seven oral and three nasal vowels. In contrast with the North West Yoruba, the South East Yoruba has retained the /gh/ and /gw/ contrast, while it has lowered the nasal vowels, /in/ and /un/ to /en/ and /on/ respectively. Central Yoruba dialect forms a transitional area in the sense that the lexicon has so much in common with the North-West Yoruba. The vowel system of the Central Yoruba is the most stable of the three dialect groups. This dialect group has retained nine oral-vowel contrasts and seven nasal vowels and has an extensive vowel harmony system. The findings were relevant to this study which looked at phonological differences of Tugen sub-dialects.

Malou [3] considered the aspects of breathiness in the Dinka vowel system and the role it plays. He discussed the physiology and definition of the vowel breathiness and the importance of tone, vowel length and vowel centralisation in the Dinka language. He points out that the breathiness is distinctive and that there are eight distinct vowel sounds in Dinka. Given that he looks at sounds in the Dinka vowel system, his work is relevant to this study which sought to look at the phonology of the Tugen sub-dialects.

Jerono [4] on Tugen word order, a minimalist perspective, gives a description of the language features that are used in sentence structures. Her study included nouns and their inflexions, case marking verbs and their inflectionally and derivationally features. In reference to word borrowing in the language, most of the loan words fit into the regular system for nouns, i.e. they inflect the definiteness and number. While looking at morphology, she says that the major processes in the language are affixation and suprafixation. This study dwelt on Tugen as a language while the current one examined the Tugen sub-dialects, Aror and Somor. It also examined phonological differences of the subdialects.

Research has been carried out on the various aspects of the Pokot, Nandi, Kipsigis and other Kalenjin dialects. Indeed serious research on the Kalenjin dates back to the colonial period. Ochieng [5] describes the emergence and the spread of the Kalenjin tribes. He gives a detailed description of the spread and the activities of each of the Kalenjin groups. He argues that the origin of the Kalenjin is within Kenya and not outside, as argued by other scholars. Ogot [6] gives the Kalenjin dialects, which he calls tribes as, Kipsigis, Nandi, Terik, Elgeiyo, Tugen, Marakwet, Kony and Sebei. Ogot groups these dialects into three main "dialects clusters". He names them as Pokot, Elgon and Southern Kalenjin dialects which include Marakwet, Tugen, Terik Elgeiyo and Kipsigis. However, he does not point out that there are sub-dialects within the said dialects. The present study analysed the phonological differences between the Tugen sub-dialects of Baringo County.

Towett [7] covers the main areas of the Kalenjin language. He describes the lexical, morphological and the syntactic aspects of the language. His work is thus descriptive. Towett gives a list of the Kalenjin dialects in order of their numerical strength as Kipsigis, Nandi + Terik, Keiyo+ Marakwet, Tugen, Sebei, Pokot. Towett's study is on the Kalenjin dialect, but the current study looked at the sub-dialects of the Tugen dialect. The Tugen is one of the dialects of the Kalenjin language.

The Kalenjin group of languages is spoken mainly in Western Kenya. Seroney [8] elaborates that Kalenjin language is spoken by close to six million people in Kenya and a substantial number in Uganda (Sebei) and Tanzania (Datoga). He classified Kalenjin 
linguistic families in Kenya as Marakwet, Nandi, Sabaot, Kipsigis Teriks, Keiyo, Tugen, Sengwer, Okiek and Pokot. About the term Kalenjin, Tucker and Bryan [9] say that the term is a cover term which means "I tell you" and was adopted by speakers as self-designating expression during the late forties and fifties and the term is now in general use in Kenya. Tapsubei and Creider [10] share this view. The name has since been taken over in the field of African Linguistics as a useful label to cover an entire language group. The dialect under study falls under the Kalenjin group.

In a study carried out by Kamuren and Bartoo [11], on a comparative study on the morpho-syntactic differences among Kalenjin Dialects, an analysis of Kipsigis, Tugen and Pokot, she pointed out that Pokot's lexical and morpho-syntactic structure is different from that of Tugen and Kipsigis while similarities were insignificant. She says the morpho-syntactic structure of Pokot is forty-two per cent similar to that of Tugen and fifty- eight per cent different. Only twenty-three morphemes correspond out of the fifty-five morphemes examined. This study looks at the morpho-syntactic differences among three Kalenjin dialects, but the current one studied the Tugen sub-dialects.

\section{METHODOLOGY}

This study used Descriptive Research Design. The study selected respondents from Baringo County who spoke the sub-dialects fluently, as part of the study sample that would be used to collect the data. The study took place in Torongo and Kabuskei locations within Baringo County. The target population was Tugen native speakers. The study employed both random and

$\begin{array}{lllll}\text { S: } & \text { Ki a }+ \text { tep } & \longrightarrow & \text { Kjate: } p \text { I asked } & \\ \text { A: } & \mathrm{Ka}+\text { tepan } & \longrightarrow & \text { Katepan I asked } & \\ \mathrm{S}: & \mathrm{Ki}+\mathrm{a}+\mathrm{Ker} & \longrightarrow & \text { Kjaker } & \text { I saw } \\ \mathrm{A}: & \mathrm{Ka}+\text { keer } & \longrightarrow & \text { Kake }: \text { r I saw } & \\ \mathrm{S}: & \mathrm{Ki}+\text { put } & \longrightarrow & \text { Kjapu }: \mathrm{t} & \text { I harvested } \\ \mathrm{A}: & \mathrm{Ka}+\text { putan } & \longrightarrow & \text { Kaput } & \text { I harvested } \\ \mathrm{S}: & \mathrm{Ki}+\mathrm{a} \text { ru } & \longrightarrow & \text { Kjaru ane } & \text { I slept } \\ \text { A: } & \mathrm{Ka}+\text { ruan } & \longrightarrow & \text { Karuan } & \text { I slept }\end{array}$

In the Somor sub-dialect, there is the formation of a palatal glide, but in Aror sub-dialect, there is no formation of a palatal glide because /a/ is a non-high vowel. The example above confirms that there are phonological differences between Tugen subdialects.

$\begin{array}{llll}\text { S: } & \mathrm{Ku}+\mathrm{a}+\mathrm{pi}: \mathrm{r} & \text { [ kwa:p:r] } & \text { I beat } \\ \mathrm{A}: & \mathrm{Kapir} & \text { [ kapir] } & \text { I beat } \\ \mathrm{S}: & \mathrm{Ku}+\mathrm{a}+\mathrm{ros} & {[\text { kwaro:s] }} & \text { I hit } \\ \mathrm{A}: & \mathrm{karos} & {[\text { karosan] }} & \text { I hit } \\ \mathrm{S}: & \mathrm{Ku}+\mathrm{a}+\mathrm{sos} & {[\text { kwasu:s] }} & \text { I bit } \\ \mathrm{A}: & \mathrm{Ka}+\mathrm{sos} & {[\text { kasosan] }} & \text { I bit } \\ \mathrm{S}: & \mathrm{Ko}+\mathrm{a}+\mathrm{rop} & {[\text { kwaro:p] }} & \text { I followed } \\ \mathrm{A}: & \text { korop } & \text { [koropan] } & \text { I followed }\end{array}$

purposive sampling procedures to select the sample from the population. 20 respondents were selected from each of the three sub-dialects. Data collection was by use of language performance test, especially designed, pilot-tested and adjusted to suit the contextual realities in the fields. The list was a total of 150 words. The administration of the language tests was conducted by the researcher with the assistance of informants. The performances were tape-recorded to capture details which were later retrieved, transcribed and analysed. Once data was collected, an analysis was done based on the objective of the study, which was to point out the phonological difference among the Tugen sub-dialects. The first step involved sorting out details according to the sub-dialects and type of data that is, word list and sentence list separately. Once transcription was done, analysis took place. A phonological analysis was carried out, and focus was on the phonemes and their phonemic properties. The differences in tone and length were then identified, highlighted and the processes involved were described.

\section{RESULTS AND FINDINGS Phonological Level}

This study revealed some phonological rules involved in the phonological variations between Tugen sub-dialects. These phonological rules include:

\section{Glide Formation}

This is a phonological process that derives the surface glides, /j/ and /w/ when high vowels are immediately followed by non-high vowels. The following section examines how these glides are formed and help bring out a difference in Tugen sub-dialects.

\section{Labio Velar Glide Formation}

This is formed when high back vowels are followed by non-high vowels. This is shown in the following examples. 
In the examples above in Somor sub-dialect the labio-velar glide is formed as the high back vowel $/ \mathrm{u} /$ and $/ \mathrm{o} /$ are followed by words beginning with nonhigh vowels. The vowels /u/ and /o/ change into a labio-

The rule for labio-velar glide can be formalised as follows:
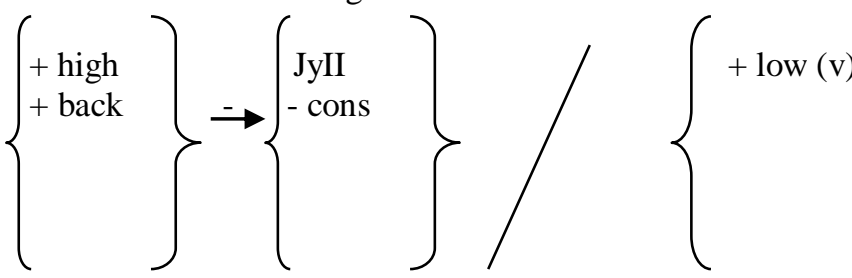

\section{Suprasegmental phonology}

\section{Negation}

Negation in the sub-dialect is marred by tonal inflexion. There are variations when negation is introduced into the various negative statements as shown below.

\section{I will not eat meat now.}

S: mo: me ane pento kuno:

A: $\underline{\text { mo:man }}$ pen kuno:

2. I will not sleep there.

$\mathrm{S}$ : Morue ane nuni

A: Morouan kuno.

3. I will not run today.

S: mowise ane ra.

A: mowisan raoni.

4. I will not herd the cows.

S: moripe ane tuka.

A: moripan tit.

5. I will not drink milk.

S: molue ane t feko.

A: moluan t $\mathrm{e}$.

From the data above, the negation in Somor sub-dialect is marked by two different tones. These are a high tone followed by a low tone. For instance, in words such as [moamisie ane] meaning 'I will not eat' and [morue ane] meaning 'I will not sleep', the tone in the first syllable is a high tone followed by a low tone so it is $(\mathrm{H}+\mathrm{L})$. However, in the Aror sub-dialect, the first syllable is characterised by the low tone in the first syllable followed by a high tone. It is described as $(\mathrm{L}+\mathrm{H})$.

This illustration shows that there are phonological differences between Tugen sub-dialects.

\section{Coalescence/ fusion}

This is a morphophonological process by which units that are separated at one level of representation are realised by a form in which there is no corresponding boundary. In Aror sub-dialect, several velar glide when they are followed by /a/. In the Arorsub-dialect labio-velar glide formation is not permitted. This confirms that there are phonological differences between Tugen sub-dialects.

words are fused into a single word, but in Somor subdialect, this does not occur. This is in relation to the possessive forms. The following examples illustrate this.

- My child is coming.

S. nonei lakwe nejo.

A. onei lakwejwane.

- My cow is sick.

S: Miani teta ne no.

A: Mianei tetnwane.

- Their goats are many. S: Sere neko t e kwat $\int$ e. A: tfana neko tfi kwatf.

- Our daughter is well.

S: Kakosop t $\int$ epto newanet.

A: kakosop t $\int$ epto nenwan.

- His shamba is big.

S: Kinto mpare ne nyin.

A: Kinto merenyin. $\int$

From the data above in Somor sub-dialect, the words [ teta ne nyo] meaning 'my cow' and[ lakwe ne nyo] meaning 'my child' have a high tone on the first syllable, followed by a low tone and another high tone hence $(\mathrm{H}+\mathrm{L}+\mathrm{H})$. However, in Aror sub-dialect, the fusion of the words into a single word in words such as [lakwengwane] meaning 'my child' and [tetngwane] 'my cow' has a low tone on the first syllable followed by another low tone on the second syllable and a high tone on the last syllable. The tone is, therefore $(\mathrm{L}+\mathrm{L}+\mathrm{H})$. This shows that there are phonological differences between Somor and Aror sub-dialects.

\section{Definiteness}

Tone is not confined to one segment but spreads to adjacent segments. This happens when root words are inflected for definiteness. This is marked by suffixation as shown below. 


\section{Somor}

Orthographic repr

/lakwe- lakwee/

/tapte-taptee/

/soke-soke:k/

/keleek-ke:le:k/

\section{Aror}

Orthographic repr

/lakwa-lakwe/

/tapta-tapte/

/sok-sokek/

/kelta-kelat/

phonemic repr
[lakwe]
[tapte:]
[soke:k]
[ke le:k]


Phonemic repr
[lakwe]
[tapte]
[sokek]
[kelat]

Gloss

child

flower

leaves

teeth

In Somor sub-dialect, when the root words are inflected for definiteness, there are changes in the tone. For instance, in the words [lakwe:] meaning 'child' the tone in the first syllable is a low tone followed by a high tone in the second syllable. Another example is the word [tapte:] meaning 'flower'. The first syllable has a low tone, followed by a high tone on the second. Hence the tones are $(\mathrm{L}+\mathrm{H})$.

In Aror sub-dialect, there is no change in the tone. In the word [lakwe] meaning 'child' and [tapte] meaning 'flower', the first syllable has a low tone followed by another low tone. The tone is hence $(\mathrm{L}+\mathrm{L})$.

The data above illustrates that there are phonological differences between Somor and Aror subdialects of the Tugen dialect.

\section{CONCLUSION AND RECOMMENDATIONS}

Data on the phonological aspect was collected by the use of the Swadesh list. The analysis was made possible through the Natural Generative Phonology theory for phonological analysis. From the study, it was found that Aror and Somor sub-dialects in relation to tone had pronunciation differences which helped with the identification of the sub-dialects. In both subdialects, it was found that tone and length played both grammatical and lexical roles of contrasting meaning. Several factors have contributed to this. First of all is the geographical location of the sub-dialects under consideration. Geographical aspect is major factor that influences language or dialect behaviour. If two or more languages or dialects interact more often, they are bound to influence each other linguistically. This linguistic influence had a direct effect on area under discussion that is phonology. The study provided evidence that the two sub-dialects have some linguistic variations at the phonological level. At this level, various phonological processes brought out the differences in the sub-dialects. Having carried out the investigation successfully, the following are the recommendations. Since the Kalenjin language has many dialects and only one of these was considered, it

Gloss

child

flower

leaves

teeth

is recommended that a larger study that would include all other dialects, including those outside Kenya, be carried out in order to come up with a more meaningful dialectological study of the Kalenjin language. More studies also need to be conducted on the phonology and morphology of the Tugen dialect, using modern theories of morphophonemic description. More studies should also be done on the Somor attitude towards Aror and Aror attitude towards Somor.

\section{REFERENCES}

1. Muazu, M. A. (2010). Miship: People, language and dialects. California Linguistic Notes, 35(2).

2. Mambwe, K. (2008). Some linguistic variations of Kaonde: A dialectological study. (Unpublished M.A Dissertation). Lusaka: University of Zambia.

3. Malou, J. (1988). Dinka vowel system. Dallas, TX: Summer Institute of Linguistics.

4. Jerono, P. (2012). Tugen word order. A minimalist program. Unpublished $\mathrm{PhD}$ Dissertation, University Of Nairobi.

5. Ochieng, W. R. (1975). An outline of the history of the Rift Valley of Kenya until 1900. Kampala: East African Literature Bureau.

6. Ogot, B. A. (1976). Kenya before 1900. Nairobi: East African Publishing House.

7. Towett. (1979). A Study of Kalenjin Linguistic. Nairobi: Kenya Literature Bureau.

8. Seroney, K. (2009). Samburtaab Ngaleekab Kaleenchin. Kalenjin Dictionary. Nairobi: Mvule Africa Publishers.

9. Tucker, A., \& Bryan, M. A. (1964). Noun classification in Kalenjin: Nandi - Kipsigis. London: School of Oriental and African Studies, University of London.

10. Tapsubei, J. C., \& Creider, C. (2001). A Dictionary of the Nandi Language. Köln, Rüdiger Köppe.

11. Kamuren, F., \& Bartoo, P. (2012). The morphosyntactic differences among Kalenjin dialects: An analysis of Kipsigis, Tugen and Pokot. International Knowledge Sharing Platform, 2(7). 